\title{
The Pulmonologist's role in Caring for Pregnant Women with Regard to the Reproductive Risks of Diagnostic Radiological Studies or Radiation Therapy
}

Robert Brent, MD, PhD, DSc ${ }^{a, b, *}$

\author{
KEYWORDS \\ - Pulmonologist $\bullet$ Exposure $\bullet$ Pregnant $\bullet$ Radiological studies
}

Almost every practicing physician is aware that the use of diagnostic radiological techniques and radiation therapy using ionizing radiation has increased substantially over the past 30 years. ${ }^{1}$ In 1980 , the US population received $20 \%$ of their exposure to ionizing radiation from medical care. The National Council on Radiation Protection and Measurements (NCRP) No. 160 (2009) reported that almost $50 \%$ of the population's radiation exposure came from medical care. Unfortunately, this increased exposure has been presented in the newspapers, television, and Internet, and in many instances, the risks of birth defects, miscarriage, and cancer have been exaggerated and the benefits ignored. It is important for physicians to become as knowledgeable about the risks of ionizing radiation as they are about its benefits. Although pulmonologists do not concentrate their practice on pregnant women or women of reproductive age, these patients are a part of their practice. An important concern is that many women visit their physician, without knowing that they are pregnant or worse, they become pregnant between the time of the office visit and the appointment for the radiological examination. These situations can be concerning for the patient and the physician. In order for the physician to interpret the various forms of exposure measurement, Table 1 lists the various nomenclatures for radiation exposures, so that the reader will be able to understand radiation exposures in the terms with which they may be familiar.

Pulmonologists are fortunate with regard to the specific studies they request to provide clinical care because most of the diagnostic tests do not directly expose the uterus (embryo) or ovary. Radiography of the chest, head, neck, teeth, or extremity exposes the embryo or ovary to miniscule (insignificant) exposures of radiation. In some instances, there is no exposure at all.

The pulmonologists may infrequently order diagnostic studies that exposes the abdomen or

a Departments of Pediatrics, Radiology, Pathology, Anatomy and Cell Biology, Thomas Jefferson University, 1025 Walnut Street, Philadelphia, PA 19107, USA

b Clinical and Environmental Teratology Laboratory, Research Department, Alfred I. duPont Hospital for Children, PO Box 269, Wilmington, DE 19899, USA

* Clinical and Environmental Teratology Laboratory, Research Department, Alfred I. duPont Hospital for Children, PO Box 269, Wilmington, DE 19899.

E-mail address: rbrent@nemours.org 
Table 1

lonizing radiation exposure terminology

\begin{tabular}{llll} 
Rad/Rem & Millirad/Millirem & Gray (Gy), Milligray (mGy) & Sievert (Sv), Millisievert (mSv) \\
\hline 0.001 & 1 & $0.01 \mathrm{mGy}$ & $0.01 \mathrm{mSv}$ \\
\hline 0.01 & 10 & $0.1 \mathrm{mGy}$ & $0.1 \mathrm{mSv}$ \\
\hline 0.1 & 100 & $1 \mathrm{mGy}$ & $1 \mathrm{mSv}$ \\
\hline 1 & 1000 & $0.01 \mathrm{~Gy}$ & $0.01 \mathrm{~Sv}$ \\
\hline 10 & 10,000 & $0.1 \mathrm{~Gy}$ & $0.1 \mathrm{~Sv}$ \\
\hline 100 & 100,000 & $1 \mathrm{~Gy}$ & $1 \mathrm{~Sv}$ \\
\hline
\end{tabular}

The units of rad and rem and the gray and sievert are identical for exposures of low energy transfer radiation, such as $x$-rays, $\gamma$-rays, $\beta$-rays, and protons. These forms of radiation have a relative biological effectiveness (RBE) rated at one. Exposures to $\alpha$-rays and neutrons have a biologic effectiveness greater than one. The rem and the sievert take into consideration the RBE of the radiation. For clinicians, the RBE is infrequently relevant because most radiological procedures use radiation with an RBE of 1 so the gray and sievert exposures will be identical.

pelvis to radiation but they should be aware of other studies that could have been ordered by other providers. The vast majority of diagnostic studies exposing the abdomen or pelvis to radiation also expose the embryo or ovary to less than $10 \mathrm{rad}(0.1 \mathrm{~Gy})$.

\section{THE REPRODUCTIVE AND DEVELOPMENTAL RISKS OF EXPOSURES OF IONIZING RADIATION TO PREGNANT OR POTENTIALLY PREGNANT WOMEN}

The reproductive and developmental risks of in utero exposures to ionizing radiation are listed below (Tables 2 and $\mathbf{3}$ ).

1. Birth defects, mental retardation, other neurobehavioral effects, growth retardation, and embryonic death (miscarriage) are deterministic effects (threshold effects). These effects have a no observed adverse effect level (NOAEL). Almost all diagnostic radiological procedures provide exposures that are below the NOAEL for these developmental effects. Diagnostic radiological studies rarely exceed 10-rad (0.1 Gy) exposure, whereas the threshold for congenital malformations or miscarriage is more than 20 rad (0.2 Gy) (see Table 2).

2. In order for the embryo to be deleteriously affected by ionizing radiation when the mother is exposed to a diagnostic study, the embryo has to be exposed above the NOAEL to increase the risk of deterministic effects. This scenario rarely happens when pregnant women undergo radiographic studies of the head, neck, chest, or extremities.

3. During the preimplantation and preorganogenesis stages of embryonic development, the embryo is least likely to be malformed by the effects of ionizing radiation because the cells of the very young embryo are omnipotent and can replace adjacent cells that have been deleteriously affected. This early period of development has been designated as "the all or none period."

4. Protraction and fractionation of exposures of ionizing radiation to the embryo decrease the magnitude of the deleterious effects of deterministic effects. The more protracted or fractionated the radiation, the lower the risk because the threshold increases.

5. The increased risk of cancer following high level of exposures to ionizing radiation in adult populations has been demonstrated in the survivors of atomic bomb. Radiation-induced carcinogenesis is assumed to be a stochastic effect (nonthreshold effect), so that there is theoretically a risk at low-level exposures. While there is no question that high-level exposures of ionizing radiation can increase the risk of cancer, the magnitude of cancer risk from embryonic exposures following diagnostic radiological procedures is controversial. Recent publications and analyses indicate that the risk is lower for the irradiated embryo than the irradiated child, which surprised many scientists interested in this subject (Tables 4-6). ${ }^{2}$

\section{EVALUATING THE RISKS OF RADIATION EXPOSURE TO THE DEVELOPING EMBRYO}

When evaluating the risks of ionizing radiation, the physician is faced with several different clinical situations:

\section{Situation 1}

The pulmonologists are fortunate because the radiological tests that would be ordered for their patients do not expose the embryo directly, and therefore, the embryo does not receive an exposure that would increase the risk for birth defects, 


\begin{tabular}{|c|c|}
\hline Stage, Gestation Weeks & Effect \\
\hline $\begin{array}{l}\text { First and second week after last } \\
\text { menstrual period (before conception) }\end{array}$ & $\begin{array}{l}\text { First } 2 \text { wk after the first day of the last menstrual period. } \\
\text { This is preconception radiation. Mother has not yet } \\
\text { ovulated }\end{array}$ \\
\hline $\begin{array}{l}\text { Third and fourth week of gestation } \\
\text { (first } 2 \text { wk postconception) }\end{array}$ & $\begin{array}{l}\text { Minimum acute lethal dose in humans (from animal } \\
\text { studies). Approximately } 0.15-0.20 \text { Gy. Most sensitive } \\
\text { period for the induction of embryonic death. No } \\
\text { increase in risk of malformations in surviving fetuses. All } \\
\text { or none stage }\end{array}$ \\
\hline $\begin{array}{l}\text { Fourth to eighth week of gestation } \\
\text { (second to sixth week postconception) }\end{array}$ & $\begin{array}{l}\text { Minimum lethal dose (from animal studies). At } 18 \mathrm{~d} \\
\text { postconception, } 0.25 \mathrm{~Gy} \text { ( } 25 \mathrm{rad} \text { ). After } 50 \text { days } \\
\text { postconception, }>0.50 \mathrm{~Gy} \text { ( } 50 \mathrm{rad} \text { ) } \\
\text { Embryo is vulnerable to the induction of major } \\
\text { malformations. Threshold for malformations is }>0.2-0.5 \\
\text { Gy, depending on the malformation } \\
\text { Minimum dose for growth retardation. At } 18-36 \mathrm{~d} \text {, } \\
0.20-0.50 \mathrm{~Gy}(20-50 \mathrm{rad}) \text {. At } 36-110 \mathrm{~d}, 0.25-0.50 \mathrm{~Gy} \\
(25-50 \mathrm{rad}) \text { But the induced growth retardation during } \\
\text { this period is not as severe as during midgestation }(8-15 \\
\text { wk) from similar exposures and is more recuperable }{ }^{19} \\
\end{array}$ \\
\hline Eighth to fifteenth week of gestation & $\begin{array}{l}\text { Most sensitive period for irreversible whole body growth } \\
\text { retardation, microcephaly, and severe mental } \\
\text { retardation. Threshold for severe metal retardation is } \\
0.35-0.50 \mathrm{~Gy}(35-50 \mathrm{rad}) \text {. Miller }{ }^{20} \text { believes the } \\
\text { threshold is }>0.5 \mathrm{~Gy} \text {. Decrease in IQ can occur at lower } \\
\text { exposures }\end{array}$ \\
\hline Sixteenth week to term of gestation & $\begin{array}{l}\text { Higher exposures can produce growth retardation and } \\
\text { decreased brain size and intellect, although the effects } \\
\text { are not as severe as those from similar exposures during } \\
\text { midgestation. There is no documented risk for major } \\
\text { anatomic malformations. Minimum lethal dose } \\
\text { threshold for mental retardation (from animal studies) is } \\
\text { from } 15 \text { wk to term }>1.5 \mathrm{~Gy}(150 \mathrm{rad}), \text { but decrease in IQ } \\
\text { can occur at lower exposures }\end{array}$ \\
\hline
\end{tabular}

There is no evidence that radiation exposure in the diagnostic ranges ( $<0.10 \mathrm{~Gy},<10 \mathrm{rad}$ ) is associated with measurably increased incidence of congenital malformation, stillbirth, miscarriage, growth retardation, or mental retardation.

miscarriage, growth retardation, mental retardation, or neural behavioral effects (Table 7). Table 7 lists the frequently used diagnostic radiological and radionuclide tests. None of the tests exceed exposures of $10 \mathrm{rad}(0.1$ Gy or $100 \mathrm{mGy})$ except for radiation therapy or extensive fluoroscopy to the abdomen or pelvis.

Although most diagnostic radiological studies of the abdomen or pelvis do not expose the embryo to more than $10 \mathrm{rad}(0.10 \mathrm{~Gy})$, the family is upset because they are aware that the embryo was directly exposed. Under these circumstances it may be necessary to request the health physicist to calculate the actual exposure to allay the family's concern.

\section{Situation 2}

The pregnant patient presents with clinical symptoms that need to be evaluated. What is the appropriate use of diagnostic radiological procedures that may expose the embryo or fetus to ionizing radiation?

A pregnant or possibly pregnant woman complaining of chest symptoms that cannot be attributed to pregnancy deserves the appropriate studies to diagnose and treat the clinical problems, including radiological studies. Furthermore, these studies should not be relegated to one portion of the menstrual cycle if the patient has not yet missed her period. The studies should be performed at the time they are clinically indicated whether or not the patient is in the first or second half of the menstrual cycle. During the second half of the menstrual cycle the pregnancy test result may be negative even though the patient is pregnant. This situation should be explained to the patient and the family. 
Table 3

Reproductive risks per million recognized pregnancies

\section{Reproductive Risks}

Frequency

Immunologically and clinically diagnosed spontaneous abortions per million 350,000

conceptions ( $<20 \%$ has lethal malformations or chromosomal abnormalities that cause abortion before the first month of gestation)

Clinically recognized spontaneous abortions per million clinically recognized pregnancies. Spontaneous abortion after the first missed menstrual period

\begin{tabular}{ll}
\hline Genetic diseases per million births & 110,000 \\
\hline Multifactorial or polygenic genetic environmental interactions) & 90,000 \\
\hline Dominantly inherited disease & 10,000 \\
\hline Autosomal and sex-linked genetic disease & 1200 \\
\hline Cytogenetic (chromosomal abnormalities) & 5000 \\
\hline Major malformations (genetic, unknown, environmental) & 3000 \\
\hline Prematurity (Ireland 55,000; United States 124,000) & 30,000 \\
\hline Fetal growth retardation & 69,000 \\
\hline Stillbirths (>20 wk) & 30,000 \\
\hline Infertility & $4000-20,900$ \\
\hline
\end{tabular}

Data from Brent RL. Utilization of developmental basic science principles in the evaluation of reproductive risks from preand postconception environmental radiation exposures. Teratology 1999;59:182-204.

\section{Situation 3}

A patient has completed a diagnostic procedure that has exposed her uterus to ionizing radiation. Her pregnancy test result was negative. She believes she was pregnant at the time of the procedure. What is your response to this situation?

Explain that you would have proceeded with the necessary radiological diagnostic test whether the patient was pregnant or not because diagnostic studies that are indicated in the patient have to take priority over the possible risk to her embryo; however, almost $100 \%$ of diagnostic studies do not increase the risks to the embryo (see Table 1). Second, she must have been very early in her pregnancy because her pregnancy test result was negative. At this time, obtain the calculated dose to the embryo and determine her stage of pregnancy. If the dose is less than $10 \mathrm{rad}(0.1$ Gy; $0.1 \mathrm{~Sv}$ ), you can inform the patient that her

\section{Table 4}

Risk of 10 -rad $(0.1 \mathrm{~Gy})$ exposure to the embryo

\begin{tabular}{|c|c|c|}
\hline Risks & $\begin{array}{l}\text { Background Incidence } \\
\text { (per } 10^{6} \text { pregnancies) }\end{array}$ & $\begin{array}{l}\text { Additional Risk of } 10 \text {-rad } \\
(0.1 \mathrm{~Gy}) \text { Exposure }\end{array}$ \\
\hline $\begin{array}{l}\text { Very early pregnancy loss, before the } \\
\text { first missed period }\end{array}$ & 350,000 & 0 \\
\hline $\begin{array}{l}\text { Spontaneous abortion in a known } \\
\text { pregnant women }\end{array}$ & 150,000 & 0 \\
\hline Major congenital malformations & 30,000 & 0 \\
\hline Severe mental retardation & 5000 & 0 \\
\hline Childhood leukemia per year & 40 & $\begin{array}{l}\text { Very low increased risk, and possibly } \\
\text { no measurably identifiable } \\
\text { increased risk }\end{array}$ \\
\hline Early- or late-onset genetic disease & 100,000 & Very low risk in next generation \\
\hline Prematurity & 69,000 & 0 \\
\hline Growth retardation & 30,000 & 0 \\
\hline Stillbirth & $20-2000$ & 0 \\
\hline Infertility & $7 \%$ of couples & 0 \\
\hline
\end{tabular}




\section{Table 5}

Follow-up of adults with solid cancers in Hiroshima and Nagasaki, who were in utero at the time of detonation of the atomic bombs in 1945

\begin{tabular}{lllll} 
Dose in Sv $(\mathrm{rad})$ & No. of Patients & No. of Cancers & Person-Years & $\begin{array}{l}\text { Percentage with } \\
\text { Solid Cancers }\end{array}$ \\
\hline$<0.005(<0.5)$ & 1547 & 54 & 49,326 & 3.5 \\
\hline $0.005-<0.1(0.5-10.0)$ & 435 & 16 & 14,005 & 3.7 \\
\hline $0.1-<0.2(10-<20)$ & 168 & 6 & 5041 & 3.6 \\
\hline $0.2-<0.5(20-<50)$ & 172 & 8 & 5496 & 4.6 \\
\hline $0.5-<1.0(50-<100)$ & 92 & 7 & 2771 & 7.6 \\
\hline$>1$ & 48 & 3 & 1404 & 6.2 \\
\hline Total & 2452 & 94 & 94 & 3.5 \\
\hline
\end{tabular}

Data from Preston $\mathrm{DL}$, Cullings $\mathrm{H}$, Suyama $\mathrm{A}$, et al. Solid cancer incidence in atomic bomb survivors exposed in utero or as young children. J Natl Cancer Inst 2008;100:428-36.

risks for birth defects and miscarriage have not been increased. In fact, the threshold for these effects is $20 \mathrm{rad}(0.2 \mathrm{~Gy})$ at the most sensitive stage of embryonic development (see Table 2). Of course, you are obligated to tell the patient that every healthy woman is at risk for the background incidence of birth defects and miscarriage, which is $3 \%$ for birth defects and $15 \%$ for miscarriage (see Table 3).

\section{Situation 4}

A woman delivers a baby with serious birth defects. On her first postpartum visit, she recalls that she had a diagnostic radiological study early in her pregnancy. What is your response when she asks you whether the baby's malformation could be caused by the radiation exposure?

In most instances, the nature of the clinical malformations can rule out radiation teratogenesis (microcephaly, mental retardation, and fetal growth retardation). In such a case, a clinical teratologist or radiation embryologist could be of assistance. On the other hand, if the exposure is less than $10 \mathrm{rad}(0.1 \mathrm{~Gy})$, it would not be scientifically supportable to indicate that the radiation exposure was the cause of the malformation. The threshold for malformations is $20 \mathrm{rad}(0.2 \mathrm{~Gy})$ (see Table 2). The dose, timing, and nature of the malformation are considered in this analysis.

To appropriately and more completely respond to these questions, the physician should rely on the extensive amount of available information on the effects of radiation on embryos. In fact, there is no environmental hazard that has been more extensively studied or on which more information is available (see Tables 2 and 4$)^{3-12}$

\section{RADIATION RISKS TO THE EMBRYO}

An acute exposure to ionizing radiation more than 50 rad represents a significant risk to the embryo, regardless of the stage of gestation. ${ }^{6-9,12,13}$ The

\begin{tabular}{|c|c|c|c|c|}
\hline Dose in Sv (rad) & No. of Patients & No. of Cancers & Person-Years & Percentage of Cancers \\
\hline$<0.005(<0.5)$ & 8549 & 318 & 247,744 & 3.7 \\
\hline $0.005-<0.1(0.5-10)$ & 4528 & 173 & 134,621 & 3.8 \\
\hline $0.1-<0.2(10-<20)$ & 853 & 38 & 25,802 & 4.4 \\
\hline $0.2-<0.5(20-<50)$ & 859 & 51 & 25,722 & 5.9 \\
\hline $0.5-<1.0(50-<100)$ & 325 & 21 & 9522 & 6.5 \\
\hline$>1$ & 274 & 48 & 7620 & 17.5 \\
\hline Total & 15,388 & 649 & 451,031 & 4.2 \\
\hline
\end{tabular}

Data from Preston DL, Cullings $\mathrm{H}$, Suyama $\mathrm{A}$, et al. Solid cancer incidence in atomic bomb survivors exposed in utero or as young children. J Natl Cancer Inst 2008;100:428-36. 
Table 7

Typical doses for selected medical procedures

\begin{tabular}{|c|c|c|c|}
\hline Type & Description & $\begin{array}{l}\text { Embryo/Fetal Dose } \\
\text { Range (mGy) }\end{array}$ & $\begin{array}{l}\text { Gonadal Dose (Ovaries, } \\
\text { Testes) (mGy) }\end{array}$ \\
\hline Radiography & Skull & $<0.01$ & $<0.01,<0.01$ \\
\hline Radiography & Chest & $<0.01$ & $<0.01,<0.01$ \\
\hline Radiography & Thoracic spine & $<0.01$ & $<0.01,<0.01$ \\
\hline Radiography & Mammography & $<0.01$ & $<0.01,<0.01$ \\
\hline Radiography & Barium meal & $0.1-1.1$ & \\
\hline Radiography & Pelvis & $0.1-1.1$ & $1.2,4.6$ \\
\hline Radiography & Lumbar spine & $1-2$ & $4.3,0.6$ \\
\hline Radiography & Abdomen & $1-3$ & $2.2,0.4$ \\
\hline Radiography & Barium enema & $7-8$ & $16,3.4$ \\
\hline $\mathrm{CT}$ & Chest/CTPA & $0.1-1$ & $0.08,<0.01$ \\
\hline$\overline{\mathrm{CT}}$ & Abdomen & $4-16$ & $8.0,0.7$ \\
\hline$\overline{\mathrm{CT}}$ & Pelvis & $10-32$ & $23,1.7$ \\
\hline Chest Fluoroscopy & Chest & $<0.1 \mathrm{mGy} / \mathrm{min}$ & \\
\hline IR fluoroscopy & Abdominal fluoroscopy & $6 \mathrm{mGy} / \mathrm{min}$ & \\
\hline Nuclear Medicine & Lung ventilation & $0.1-0.3$ & $0.13-0.5,0.13-0.5$ \\
\hline Nuclear Medicine & Lung perfusion & $0.1-0.4$ & $0.06-0.27,0.04-0.16$ \\
\hline Nuclear Medicine & White cell scan & $0.7-1.4$ & \\
\hline Nuclear Medicine & Renal scan & $3-7$ & $1.0-2.0,0.7-1.4$ \\
\hline Nuclear Medicine & Bone scan & $4.5-7.0$ & $2.7-4.0,1.8-2.7$ \\
\hline Nuclear Medicine & Cerebral blood flow & $5-10$ & $3.7-7.3,1.3-2.7$ \\
\hline Nuclear Medicine & PET & $8-16$ & $5.6-11.1,4.4-8.8$ \\
\hline Nuclear Medicine & Myocardial perfusion & $16.7-22.2$ & $9.3-12.4,2.7-3.6$ \\
\hline Nuclear Medicine & Therapy & $>50$ & 31,19 \\
\hline
\end{tabular}

Abbreviations: CT, computed tomography; CTPA, CT pulmonary angiography; PET, positron emission tomography.

threshold dose for low energy transfer ionizing radiation that results in an increase in malformations is approximately 20 rad (0.2 Gy) (see Table 2). Although congenital malformations are unlikely to be produced by radiation during the first 14 days of human development, there would be a substantial risk of embryonic loss if the dose is high. From approximately the 18th day to the 40th day postconception, the embryo would be at risk for an increased frequency of anatomic malformations if the radiation exposure exceeds 20 to $25 \mathrm{rad}$ (0.20-0.25 Gy). Until about the 15th week, the embryo has an increased susceptibility to central nervous system (CNS) effects, major CNS malformations early in gestation, and mental retardation in midgestation. Of course, with very high doses, in the hundreds of rads, mental retardation can occur in the later part of gestation. Although it is true that the embryo is vulnerable to the deleterious effects of these midrange exposures of ionizing radiation, the measurable effects fall off rapidly as the exposure approaches the usual levels that the embryo receives from diagnostic radiological procedures ( $<10 \mathrm{rad}$ [0.1 Gy]). The threshold of 20 $\operatorname{rad}(0.2 \mathrm{~Gy})$ at the most vulnerable stage of development (20-25 days postconception) is increased by protraction of the radiation exposure. If a pregnant woman had a series of radiographic analyses over a period of 3 to 4 days with a total exposure of $15 \mathrm{rad}(0.15 \mathrm{~Gy})$, there would be no increased risk for any of the developmental threshold (deterministic) effects. $6,12,13$ The recommendations of most radiation embryologists indicate that exposures in the diagnostic range do not increase the risk of birth defects or miscarriage. ${ }^{6,8,9,12}$ Table 4 compares the spontaneous risks facing an embryo at conception and the risks from a low-level exposure of ionizing radiation (10 rad; $100 \mathrm{mGy} ; 10,000 \mathrm{mrad}$ ).

Therefore, the hazards of exposures in the range of diagnostic radiological studies $(20-10,000$ mrad [0.2 mGy-0.1 Gy]) present an extremely low risk to the embryo when compared with the spontaneous mishaps that can befall human embryos (see Tables 3 and 4). Approximately 
$30 \%$ to $40 \%$ of human embryos abort spontaneously (many abort before the first missed menstrual period) (see Table 3). Human infants have a $3 \%$ major malformation rate at term that increases to approximately $6 \%$ to $8 \%$ once all minor malformations are recorded. Although doses from 1 to $3 \mathrm{rad}(0.01-0.03 \mathrm{~Gy})$ can produce cellular effects and diagnostic radiation exposure during pregnancy has been associated with malignancy in childhood, the maximum theoretic risk to human embryos exposed to doses of $10 \mathrm{rad}(0.1$ Gy) or less is extremely small. When the data and risks are explained to the patient, the family with a wanted pregnancy invariably continues with the pregnancy.

A frequent difficulty is that the risks from diagnostic radiation exposure are evaluated outside the context of the significant normal risks of pregnancy. Furthermore, many physicians approach the evaluation of diagnostic radiation exposure with either of the 2 extremes: a cavalier attitude or panic. The usual procedures in clinical medicine are ignored, and an opinion based on meager information is given to the patient. Frequently, this attitude reflects the physician's bias about radiation effects or his or her ignorance of radiation biology. We have patient records in our files of scores of patients who were not properly evaluated but were advised to have an abortion following radiation exposure. The following case history is an example.

\section{CASE REPORT}

A 33-year-old woman was diagnosed with breast cancer and radiation therapy for the breast was initiated. Four weeks into her therapy, it was discovered that she was 11 weeks pregnant. The oncologist, radiation therapist, and surgeon encouraged the patient and her family to abort the pregnancy. She already had received 3800 rad (3.8 Gy) to the breast. The family asked for another opinion, and our counseling service was contacted. The health physicist at the consultee institution had calculated that the fetus had received 50 rad ( 0.5 Gy) over a period of almost 4 weeks. On each day of therapy the fetus had received 0.9 rad $(0.009 \mathrm{~Gy})$. Each week the fetus had 2 days without being exposed. The patient's physicians still suggested a therapeutic abortion but with less certainty. They asked me what I would tell her. I said, "I would not tell her anything. I wanted to talk with her."

When we were able to talk, she immediately asked what should she do. I responded, "Do you have any questions?" She asked, "Could my baby be malformed?" I told her that $3 \%$ of babies are malformed and this is the background incidence. But in her case, the fetus's risks for major birth defects were not increased for 2 reasons: (1) the radiation therapy was initiated in the seventh week after all the organs had formed and (2) more important, the dose each day was too low to produce malformations at any stage of pregnancy. Then she asked whether her baby could be severely mentally retarded. I answered her in the negative. But I also had to tell her that 1 in 200 children is born mentally retarded. She then asked whether the baby could be growth retarded. I responded that $4 \%$ of newborns are growth retarded but that the radiation exposure would not cause significant growth retardation. Finally, she asked, "Could my baby be normal?" I said, "Yes."

The mother decided against abortion and delivered a 3-kg baby boy who was physically normal and has been developing, according to the mother, very normally.

\section{EVALUATING THE PATIENT}

Case histories are transmitted to our laboratory frequently. In 2008, we had 2,200,000 hits on our pregnancy Web site of the Health Physics Society, "Ask the Expert." There were 760,000 downloads and 1646 direct consultations. In most instances, the dose to the embryo is less than $10 \mathrm{rad}(0.1 \mathrm{~Gy})$ and is frequently more than $1 \mathrm{rad}(0.01 \mathrm{~Gy})$. Our experience has taught us that there are many variables involved in radiation exposure to a pregnant or potentially pregnant woman. Therefore, there is no routine or predetermined advice that can be given in this situation. However, if the physician takes a systematic approach for the evaluation of the possible effects of radiation exposure, he or she can help the patient make an informed decision about continuing the pregnancy. This systematic evaluation can begin only when the following information has been obtained:

- Stage of pregnancy at the time of exposure

- Menstrual history

- Previous pregnancy history

- Family history of congenital malformations and miscarriages

- Other potentially harmful environmental factors during the pregnancy

- Ages of the mother and father

- Type of radiation study and dates and number of studies performed

- Calculation of the embryonic exposure by a medical physicist or competent radiologist

- Status of the pregnancy, wanted or unwanted. 
The evaluation should be concluded, with both patient and counselor arriving at a decision. The physician should provide a summary in the medical record, stating that the patient has been informed that every pregnancy has a significant risk of problems and that the decision to continue the pregnancy does not mean that the counselor is guaranteeing the outcome of the pregnancy. The use of amniocentesis and ultrasonography to evaluate the fetus is an individual decision to be made in each pregnancy.

Each consultation should include the following statement. "If you are healthy, young (under 35) and have no personal or family history of reproductive or fetal developmental problems, then you began this pregnancy with a risk of $3 \%$ for birth defects and $15 \%$ for miscarriage. These are background risks faced by all pregnant women. Good luck with this pregnancy and keep in touch."

\section{THE CARCINOGENIC EFFECTS OF RADIATION}

The carcinogenic risks of in utero radiation is an important topic that cannot be addressed adequately in this article. In 1956, Stewart and colleagues $^{13}$ published the results of their casecontrol studies indicating the diagnostic radiation from pelvimetry was associated with a 50\% increased risk of childhood leukemia (see Table 4). The risk of childhood leukemia could thus increase from 40 cases per million to 60 cases per million in the population of radiation-exposed fetuses. This issue has been a very controversial subject. ${ }^{12-17}$ Preston and colleagues ${ }^{2}$ presented data from the in utero population of the atomic bomb survivors, and the data indicated that the embryo was less vulnerable to the oncogenic effects of ionizing radiation than a child. It seems that the embryo is much less vulnerable to the oncogenic effects of radiation than previous investigators have believed. Patients can be told that the fetal risk is extremely small to be measured and also because a large exposed population would be necessary (see Tables 3-5). Even if one accepts the controversy that the embryo is more vulnerable to the carcinogenic effects of radiation than a child, the risk at these low-level exposures is extremely smaller than spontaneous risks. ${ }^{1}$ Furthermore, other studies indicate that Stewart and colleagues'13 estimate of the risk involved is exaggerated. ${ }^{10,11,15-17}$

\section{DIAGNOSTIC OR THERAPEUTIC ABDOMINAL RADIATION IN WOMEN OF REPRODUCTIVE AGE}

In women of reproductive age, it is important for the patient and the physician to be aware of the pregnancy status of the patient before performing any type of radiological procedure in which the ovaries or uterus is exposed. If the embryonic exposure is $10 \mathrm{rad}(0.1 \mathrm{~Gy})$ or less, the radiation risk to the embryo are very small when compared with the spontaneous risks (see Tables 2-5). Even if the exposure is $10 \mathrm{rad}(0.1 \mathrm{~Gy})$, this exposure is far from the threshold or no-effect dose of $20 \mathrm{rad}$ (0.2 Gy). The patient will accept this information if it is offered as part of the preparation for the radiological studies at a time when both the physician and patient are aware that a pregnancy exists or may exist. The pregnancy status of the patient should be determined and noted.

Because the risks of 10-rad (0.1 Gy) fetal irradiation are so small, the immediate medical care of the mother should take priority over the risks of diagnostic radiation exposure to the embryo. Radiological studies that are essential for optimal medical care of the mother and evaluation of medical problems that need to be diagnosed or treated should not be postponed. Elective procedures such as employment examinations or follow-up examinations, once a diagnosis has been made, need not be performed on a pregnant woman even though the risk to the embryo is very small. If other procedures (eg, magnetic resonance imaging or ultrasonography) can provide adequate information without exposing the embryo to ionizing radiation, then they should be used. Naturally, there is a period when the patient is pregnant but the pregnancy test result is negative and the menstrual history is of little use. However, the risks of exposure to $10 \mathrm{rad}(0.1 \mathrm{~Gy})$ or less are extremely small during this period of gestation (all or none period, ${ }^{4}$ first 2 weeks). The patient will benefit from knowing that the diagnostic study was indicated and should be performed even though she may be pregnant.

\section{SCHEDULING THE EXAMINATION}

When elective radiological studies need to be scheduled, it is difficult to know whether to schedule them during the first half of the menstrual cycle just before ovulation or during the second half of the menstrual cycle, when most women are not pregnant. The genetic risk of diagnostic exposures to the oocyte or the embryopathic effects on the preimplanted embryo are extremely small, and there are no data available to compare the relative risk of $10 \mathrm{rad}(0.1 \mathrm{~Gy})$ to the oocyte or the preimplanted embryo. If the diagnostic study is performed in the first 14 days of the menstrual cycle, the patient should be advised to defer conception for several months based on the assumption that the deleterious effect of radiation 
to the ovaries decreases with increasing time between radiation exposure and a subsequent ovulation? The physician is in a quandary because he may be warning the patient about a very-lowrisk phenomenon. On the other hand, avoiding conception for several months is not an insurmountable hardship. This potential genetic hazard is quite speculative for man, as indicated by the NCRP and Biological Effects of lonizing Radiation committee report dealing with preconception radiation ${ }^{1,6}$ :

"It is not known whether the interval between irradiation of the gonads and conception has a marked effect on the frequency of genetic changes in human offspring, as has been demonstrated in the female mouse. Nevertheless, it may be advised for patients receiving high doses to the gonads $(>25$ rads) to wait for several months after such exposures before conceiving additional offspring."3

Because the patients exposed during diagnostic radiological procedures absorb considerably less than $25 \mathrm{rad}(0.25 \mathrm{~Gy})$, these recommendations may be unnecessary but they involve no hardship to the patient. Because both the NCRP and International Commission on Radiological Protection have previously recommended that elective radiological examinations of the abdomen and pelvis be performed during the first part of the menstrual cycle (10-day rule, 14-day cycle) to protect the zygote from possible but largely conjectural hazards, the recommendation to avoid fertilization of recently irradiated ova perhaps merits equal attention.

\section{IMPORTANCE OF DETERMINING PREGNANCY STATUS OF PATIENTS}

If exposures less than $10 \mathrm{rad}(0.1 \mathrm{~Gy})$ do not measurably affect the exposed embryos and if it is recommended that diagnostic procedures should be performed at any time during the menstrual cycle, if necessary, for the medical care of the patient, then the question of expending energy to determine the pregnancy status of the patient arises.

There are several reasons why the physician and patient should share the burden of determining the pregnancy status before performing a radiological or nuclear medicine procedure that exposes the uterus:

1. If the physician is forced to include the possibility of pregnancy in the differential diagnosis, a small percentage of diagnostic studies may no longer be considered necessary. Early symptoms of pregnancy may mimic certain types of gastrointestinal or genitourinary disease.
2. If the physician and patient are both aware that pregnancy is a possibility and the procedure is still performed, it is much less likely that the patient will be upset if she subsequently proves to be pregnant.

3. The careful evaluation of the reproductive status of women undergoing diagnostic procedures prevents many unnecessary lawsuits. Many lawsuits are stimulated by the factor of surprise. In some instances, the jury is not concerned with cause and effect but with the fact that something was not done properly by the physicians. ${ }^{18,19}$ In this day and age, failure to communicate adequately can be interpreted as less-than-adequate medical care. Both these factors are eliminated if the patient's pregnancy status has been evaluated properly and the situation discussed adequately with the patient. Physicians should learn that practicing good technical medicine may not be good enough in a litigation-prone society. Even more important, the patient will have more confidence if the decision to continue the pregnancy is made before the radiological procedure is performed, because the necessity of performing the procedure would have been determined with the knowledge that the patient was pregnant. In every consultation dealing with the exposure of the embryo to diagnostic studies involving ionizing radiation (radiography, computed tomography, use of radionuclides) in which the reproductive risks or developmental risks for a fetus have not been increased by the radiation exposure, the patient should be informed that every healthy woman with a negative personal and genetic family reproductive history has background reproductive risks, which are $3 \%$ for birth defects and $15 \%$ for miscarriage. These background risks cannot be changed.

\section{REFERENCES}

1. National Council on Radiation Protection and Measurements. Ionizing radiation exposure of the population of the United States. Report No. 160. Washington, DC: NCRP; 2009.

2. Preston DL, Cullings $H$, Suyama $A$, et al. Solid cancer incidence in atomic bomb survivors exposed in utero or as young children. J Natl Cancer Inst 2008; 100:428-36.

3. Committee on the Biological Effects of Ionizing Radiation. BEIR VII report: the effects on populations of exposure to low levels of ionizing radiation. Washington, DC: National Academy of Science Press; 2005. p. $1-524$. 
4. National Council on Radiation Protection and Measurements. Basic radiation criteria, report No. 39. Washington, DC: NCRP; 1971.

5. Brent RL. Radiations and other physical agents. In: Wilson JG, Fraser FC, editors, In: Handbook of teratology, vol. 1. New York: Plenum Press; 1977. p. 153-223.

6. Brent RL. Utilization of developmental basic science principles in the evaluation of reproductive risks from pre- and postconception environmental radiation exposures. Teratology 1999;59:182-204.

7. Brent RL. The effects of embryonic and fetal exposure to $x$-rays and isotopes. In: Barron WM, Lindheimer MD, editors. Medical disorders during pregnancy. 3rd edition. St Louis (MO): Mosby-Yearbook, Inc; 2000. p. 586-610.

8. National Council on Radiation Protection and Measurements. Medical radiation exposure of pregnant and potentially pregnant women, report no. 54 . Washington, DC: NCRP; 1977. p. 1-32.

9. Mettler FA, Jr, Brent RL, Streffer C, et al. Pregnancy and medical radiation. In: Valentin J, editor. Annals of the International Commission on Radiological Protection (ICRP), vol. 30. Publication 84, Tarrytown (NY): Elsevier Science Inc; 2000. p. 1-43.

10. Court Brown WM, Doll R, Hill AB. Incidence of leukemia after exposure to diagnostic radiation in utero. Br Med J 1960;2:1539-45.

11. Brent RL, Lauriston S. Taylor lecture: fifty years of scientific research: the importance of scholarship and the influence of politics and controversy. Health Phys 2007;93(5):348-79.
12. Brent RL. Saving lives and changing family histories: appropriate counseling of pregnant women and men and women of reproductive age, concerning the risk of radiation exposures during and before pregnancy. Am J Obstet Gynecol 2009;200(1): 4-24.

13. Stewart A, Webb D, Giles D, et al. Malignant disease in childhood and diagnostic irradiation in utero. Lancet 1956;2:447.

14. McMahon B, Hutchinson GB. Prenatal X-ray and childhood: a review. Acta Unio Int Contra Cancrum 1964;20:1172.

15. Boice JD Jr, Miller RW. Childhood and adult cancer after intrauterine exposure to ionizing radiation. Teratology 1999;59(4):227-33.

16. Wakeford R, Little MP. Risk coefficients for childhood cancer after intrauterine irradiation: a review. Int J Radiat Biol 2003;79:203-9.

17. Brent RL. The effect of embryonic and fetal exposure to X-ray, microwaves, and ultrasound: counseling the pregnant and non-pregnant patient about these risks. Semin Oncol 1989;16: 347-69.

18. Brent RL. Litigation-produced pain, disease and suffering: an experience with congenital malformation lawsuits. Teratology 1977;16:1-14.

19. Rugh R. Low levels of x-irradiation and he early mammalian embryo. Am J Roentgenol 1962;87: 559-66.

20. Miller RW. Discussion: severe mental retardation and cancer among atomic bomb survivors exposed in utero. Teratology 1999;59:234-5. 